\title{
Statistical downscaling of daily precipitation using daily airflow and seasonal teleconnection indices
}

\author{
R. L. Wilby* \\ N ational C enter for A tmospheric Research, Boulder, C olorado 80303, USA \\ and \\ Division of G eography, University of Derby, Kedleston Road, Derby DE 22 IG B, United Kingdom
}

\begin{abstract}
M onthly or seasonal climate variability is seldom captured adequately by high-resolution statistical downscaling models. However, such deficiences may, in fact, be an artefact of the failure of many downscaling models to incorporate appropriate low-frequency predictor variables. The present study explores the possibility of using variables that characterise both the high- and low-frequency variability of daily precipitation at selected sites in the British Isles. Accordingly, 3 statistical downscaling models were calibrated by regressing daily precipitation data for sites at Durham and Kempsford, UK, against regional climate predictors for the period 1881-1935. M odel 1 employed only 1 predictor, the daily vorticity obtained from daily grid-point mean-sea-level pressure over the British Isles. M odel 2 employed both daily vorticity and seasonal North Atlantic Oscillation Indices (NAOI) as predictors. Finally, Model 3 employed daily vorticity and seasonal North Atlantic sea-surface temperature (SST) anomalies as predictors. All 3 models were validated using daily and monthly precipitation statistics at the same stations for the period 1936-1990. Although Models 2 and 3 did yield improvements in the downscaling of the monthly precipitation diagnostics, the enhancement was only modest relative to Model 1 (the vorticity-only model). Nonetheless, the preliminary results suggest that there may be some merit in using North Atlantic SST series as a downscaling predictor variable for daily/monthly precipitation in the UK. However, further research is required to determine whether or not the inclusion of teleconnection indices in downscaling schemes leads to better representations of low-frequency variability in both present and future climates when General Circulation M odel outputs are employed.
\end{abstract}

KEY WORDS: Precipitation · Downscaling · N on-stationarity · Teleconnection indices · Climate change

\section{INTRODUCTION}

General Circulation M odels (GCM s) suggest that rising concentrations of greenhouse gases will have significant consequences for global climate. What is less certain is the extent to which local, surface variables such as daily precipitation or temperature will be affected. This uncertainty arises due to the fact that the spatial resolution of GCMs (typically on the order of $50000 \mathrm{~km}^{2}$ ) is too coarse to resolve topographic and sub-grid-scale processes such as clouds, and because GCM output (particularly for precipitation) is poorly resolved at the scale of individual grid points. However, for many climate change impact analyses it is

*E-mail: r.l.wilby@derby.ac.uk precisely the sub-grid-scale processes and heterogeneity, at daily or shorter time intervals, that is required (Hostetler 1994). So-called 'downscaling' techniques have emerged as a means of bridging the divide between what climatologists can currently provide and what the impacts community currently require.

The theory and practice of downscaling is well described in the literature (e.g. Kim et al. 1984, Karl et al. 1990, Wigley et al. 1990, Giorgi \& M earns 1991, von Storch et al. 1993, Wilby \& Wigley 1997). In essence, all downscaling methods relate observed mesoscale, free-atmosphere, predictor variables (such as meansea-level pressure patterns) to observed sub-gridscale, or even station-scale, surface predictands (such as precipitation). However, the techniques differ in the means by which these empirical or physically based 

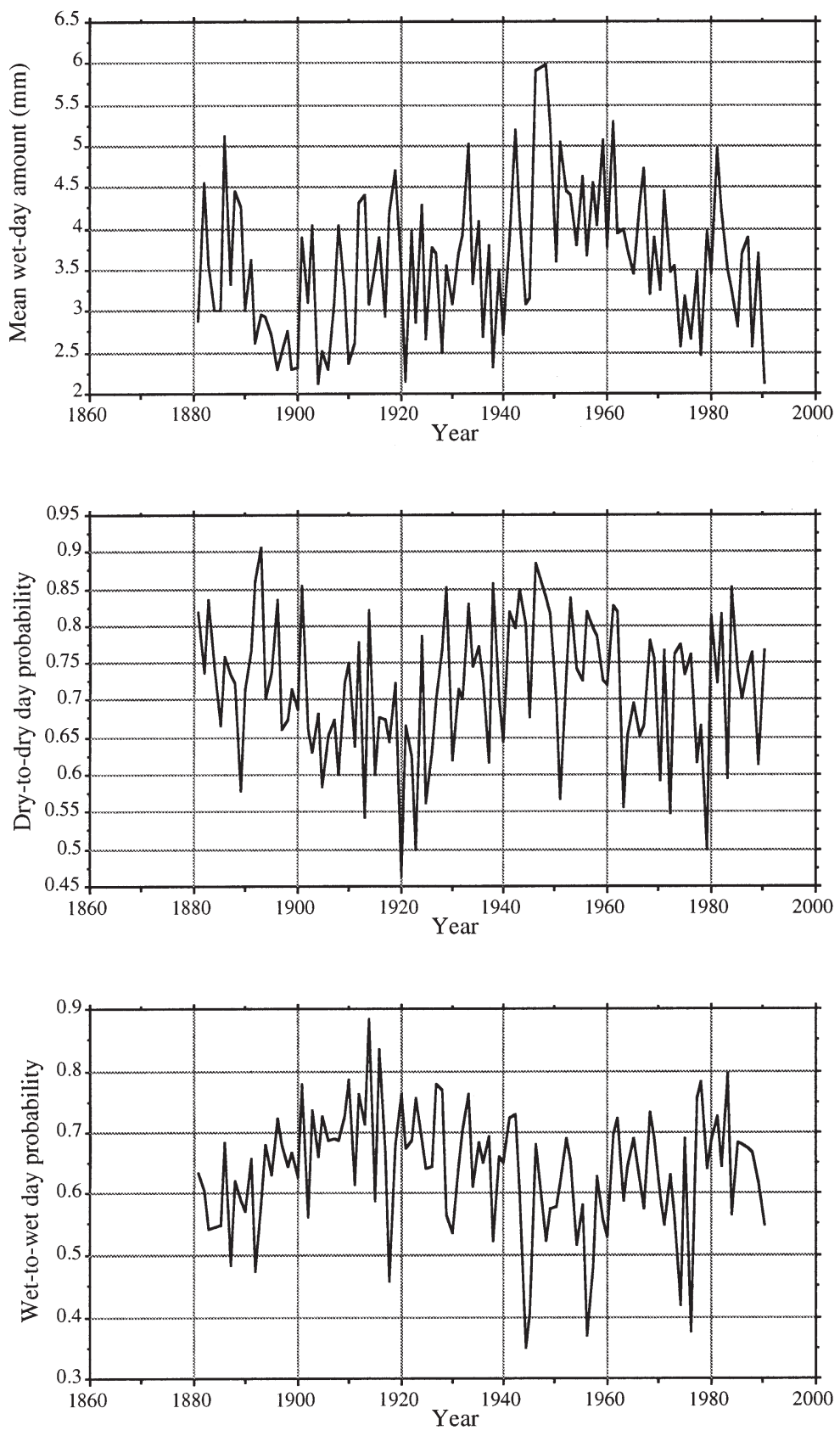

Fig. 1. Annual time-series of the spring (MAM) mean wet-day amount, $\mu$, conditional dry-day probability, $\mathrm{p}_{00}$, and conditional wet-day probability, $\mathrm{p}_{11}$, at Kempsford, UK, over the period 1881-1990

predictor-predictand relationships are established. Recent examples of the main approaches include: regression-based methods (e.g. Crane \& Hewitson 1998); resampling methods based on circulation classifications or airflow indices (e.g. Conway et al. 1996); stochastic Weather Generator (WGEN) approaches (Semenov \& Barrow 1997); and physically based Limited Area Modelling (e.g. Christensen et al. 1997). All such techniques are dependent upon the veracity of GCM output over the downscaling region of interest, on the stationarity of predictor-predictand relationships under future climate conditions, and on the selection of forcing variables relevant to the predictand of interest.

The issue of non-stationarity, in particular, may seriously undermine the realism of future climate downscaling (Wilby 1997). Unfortunately, a growing number of studies have indicated considerable variability in the relationship(s) within or between atmospheric circulation patterns and surface climate. For example, Widmann \& Schär (1997) showed that observed trends in daily precipitation across Switzerland in the period 1961-1990 could not be attributed to observed changes in the frequency of the 8 Schüepp (1979) weather classes. Rather, the precipitation trend was related to highly significant increases in the mean daily rainfall amounts that fell within major rain-producing weather types. The changes were linked to: higher low-level synoptic wind velocities during rain-producing weather episodes resulting in stronger uplift, particularly in the mountainous terrain; and to higher atmospheric temperatures and moisture leading to an overall increase in precipitation rates (Schär et al. 1996). Comparable studies of daily precipitation in the UK have attributed daily, intra-weather-class variability to changes in the dominant precipitation mechanism (whether convective or stratiform in origin) (Wilby et al. 1995), or to changes in the intensity of rain-bearing circulations and/or depression tracks (Sweeney \& O'Hare 1992). Similarly, Osborn (1997) demonstrated that the long-term mean intensity of area-average and point precipitation series can change by different relative amounts if the spatial scale of the precipitation events, and hence the fraction of wetted area, changes (for instance, from highly localised convective to more diffuse frontal rainfall).

Thus, non-stationary predictor-predictand relationships in statistical downscaling models may be attributed to 3 underlying factors: (1) an incomplete set of predictor variables that excludes low-frequency climate behaviour; (2) an inadequate sampling or calibration period for the chosen predictor-predictand relationship(s); or (3) most seriously, situations in which the climate system structure(s) changes through time. 
Table 1. Definition of daily precipitation terms

$\begin{array}{|ll|}\mu & \text { Mean wet-day amount (mm) } \\ \mathrm{p}_{00} & \begin{array}{l}\text { Conditional probability of a dry-day following a } \\ \text { dry-day }\end{array} \\ \mathrm{p}_{01} & \begin{array}{l}\text { Conditional probability of a wet-day following a } \\ \text { dry-day }\end{array} \\ \mathrm{p}_{11} & \begin{array}{l}\text { Conditional probability of a wet-day following a } \\ \text { wet-day }\end{array} \\ \pi_{\mathrm{w}} & \begin{array}{l}\text { Unconditional wet-day probability } \\ \mathrm{L}_{90 \mathrm{~d}}\end{array} \\ \mathrm{~L}_{90 \mathrm{w}} & 90 \text { th percentile dry-spell duration (d) } \\ \end{array}$

Empirical methods are not well placed to resolve case (3), whereas case (2) may be addressed using longer data sets. For example, Fig. 1 shows the time-varying behaviour of the 3 parameters (mean wet-day amount or intensity, $\mu$, conditional dry-day probability, $p_{00}$, and conditional wet-day probability, $\mathrm{p}_{11}$; see Table 1 ) that typically underpin 'chain-dependent' stochastic rainfall models (Todorovic \& Woolhiser 1975, Katz 1977). Although there is considerable inter-annual variability in the parameter values at this site, it is evident that a precipitation model of this type, calibrated using daily data for the period 1900-1920, would seriously underestimate the mean wet-day amount and overestimate wet-spell lengths if the chosen validation period was 1940-1960. However, a model calibrated using just the first half of the record, and validated using the second, might give a reasonable approximation of the statistical properties of the validation period, but not necessarily the time-series attributes.

The question is, therefore, raised as to what extent such inter-decadal variability in model parameters may be explained and reproduced by other forcing factors (case [1]), whilst at the same time preserving high-frequency variability. A number of options for addressing low-frequency variability have been explored, including: optimising the length of the calibration period (e.g. Wilby 1997); the use of mixtures of stochastic processes (e.g. Katz \& Parlange 1996); and the identification of candidate predictors using spectral analyses (e.g. Plaut et al. 1995). For example, indices such as the EI Niño Southern Oscillation Index (SOI), the Pacific N orth A merican (PNA) or the N orth Atlantic Oscillation Index (NAOI) have been used extensively to analyse global/regional variability in climate and hydrological data sets (recent publications include: Hurrell 1995, Shabbar \& Khandekar 1996, Dai et al. 1997, Rodo et al. 1997, Simmonds \& Hope 1997, Hartley \& Keables 1998, Rodriguez-Puebla et al. 1998). A number of studies have specifically considered the relationship(s) between global sea-surface temperature (SST) anomalies and/or teleconnection indices and frequencies of atmospheric circulation patterns across specific regions such as the Mediterranean (Laita \& Grimalt 1997), Europe (Fraedrich \& Muller 1992), and the British Isles (Wilby et al. 1997). Other studies have employed SST anomalies for real-time statistical forecasting of seasonal temperatures and precipitation (e.g. Colman 1997, Carson 1998), or have explicitly incorporated teleconnection indices within downscaling schemes. For example, Cavazos (1997) modelled monthly rainfall totals in N.E. Mexico using PNA, SOI and 1000-500 hPa thickness scores. Similary, Woodhouse (1997) used a set of 6 teleconnection indices (SOI, SST from the equatorial Pacific, PNA, cyclone frequencies, a southwestern trough index, and a Pacific-high southwestern-low index) to model winter rain days and average maximum temperatures at 40 to 50 climate stations across California, A rizona and New Mexico.

In the present study, both high-frequency (daily) and low-frequency (seasonal) predictor variables are employed to downscale daily precipitation at selected sites in the UK. Three daily precipitation models are compared. These are based on: (1) daily vorticity only, i.e. no low-frequency forcing; (2) daily vorticity and a seasonal index of zonal airflows, the NAOI; and (3) daily vorticity and a seasonal index of SST anomalies. In comparing the model validation results, particular attention is paid to the relative skill of each model at reproducing monthly rainfall variability. The concluding section assesses the potential gains from incorporating teleconnection indices into statistical downscaling schemes and the further research required to do this.

\section{DATA}

Four principal data sets were employed during the calibration and validation of the daily precipitation models. Firstly, daily rainfall data for 2 UK stations (Durham, northeast England and Kempsford, central southern England) were selected for the period 1881-1990 on the basis of their length and reliability (see J oyce et al. [1998] for a critique of the Durham record). Both of these sites have been employed in previous downscaling studies (e.g. Conway et al. 1996, Wilby 1997) and are used herein for further model development. Additionally, daily precipitation data for a set of 5 secondary sites (Cambridge 1901-1990, Derby 1911-1990, Norwich 1908-1990, Sandringham 1904-1990, and Wall Grange 1900-1990), which broadly represent conditions in central and eastern England, were used to investigate relationships between site rainfall and regional airflow or teleconnection indices. For the purpose of both the precipitation 
analyses and modelling a wet-day was defined as a day with a non-zero precipitation total. Note that this reduces the overall number and mean duration of dry spells because days with trace amounts $\left(<0.2 \mathrm{~mm} \mathrm{~d}^{-1}\right)$ are treated as wet-days.

Secondly, one of the 3 airflow indices used by J ones et al. (1993) to objectively reproduce the subjective British Isles weather classification system devised by Lamb (1972) was used herein as a predictor of daily precipitation parameters (renewal and intensity processes). The chosen index was the total shear vorticity $(Z)$, a measure of the degree of cyclonicity (with positive values representing cyclonic conditions and negative values anticyclonicity). The vorticity units are geostrophic and expressed as hPa per $10^{\circ}$ latitude at $55^{\circ} \mathrm{N}$. The daily vorticity was calculated for $1881-1990$ using daily grid-point sea-level pressure data measured at $5^{\circ}$ latitude by $10^{\circ}$ longitude intervals across the British Isles.

Thirdly, seasonal SST anomalies for the North A tlantic region $\left(40^{\circ}\right.$ to $60^{\circ} \mathrm{N}, 35^{\circ}$ to $\left.5^{\circ} \mathrm{E}\right)$ were obtained from the corrected GISST (Global Sea Ice and Sea Surface Temperature) data set for the period 1901-1990 (Folland \& Parker 1995). Finally, the NAOI was derived for each climatological season (i.e. DJ F, M AM, J J A and SON) using monthly mean-sea-level pressure data for Lisbon (Portugal) and Stykkisholmur (Iceland) for the period 1881-1990 (Hurrell 1995).
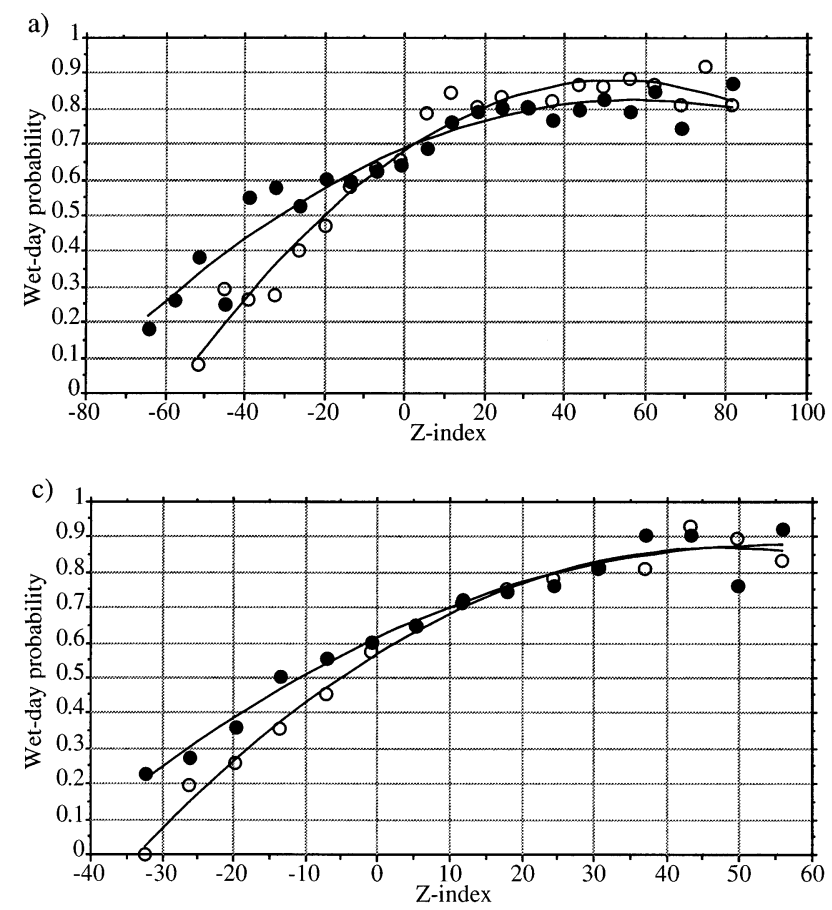

At this point it is uncertain as to how complete the chosen set of predictors is in terms of forcing precipitation at different temporal scales. The intention was to include continuous predictor variables that have been previously employed for downscaling precipitation in the British Isles (see below). The fact that these predictors do not explain all the variability in precipitation suggests that additional variables are required. However, the ultimate choice of predictors is constrained by data availability, a significant consideration when interdecadal time scales are to be considered. Under ideal circumstances a parsimonious set of predictors would be objectively selected from a comprehensive array of downscaling variables that describe the moisture content, stability, and horizontal and vertical motion of the atmosphere over the target region (Wilby $\&$ Wigley unpubl.).

\section{RELATIONSHIP BETWEEN DAILY PRECIPITATION AND REGIONAL FORCING}

Previous studies have capitalised upon the strong positive correlations between daily vorticity and daily precipitation renewal/intensity processes (e.g. Conway et al. 1996, Pilling et al. 1998, Wilby et al. 1998). Figs. $2 \& 3$ demonstrate respectively that the probability of a wet-day following a wet-day, or a wet-day fol-
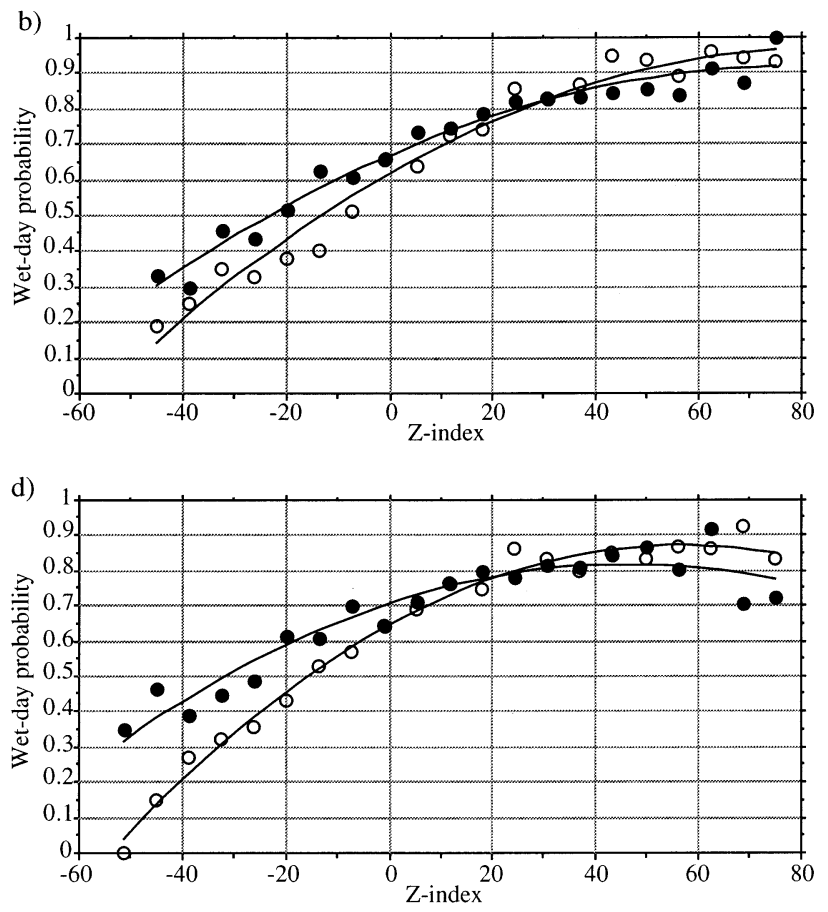

Fig. 2. Relationship between daily vorticity $(Z)$ and probability of a wet-day following a wet-day $\left(p_{11}\right)$ at Durham (o) and Kempsford (•) in (a) DJ F, (b) MAM, (c) JJ A and (d) SON, 1881-1935 

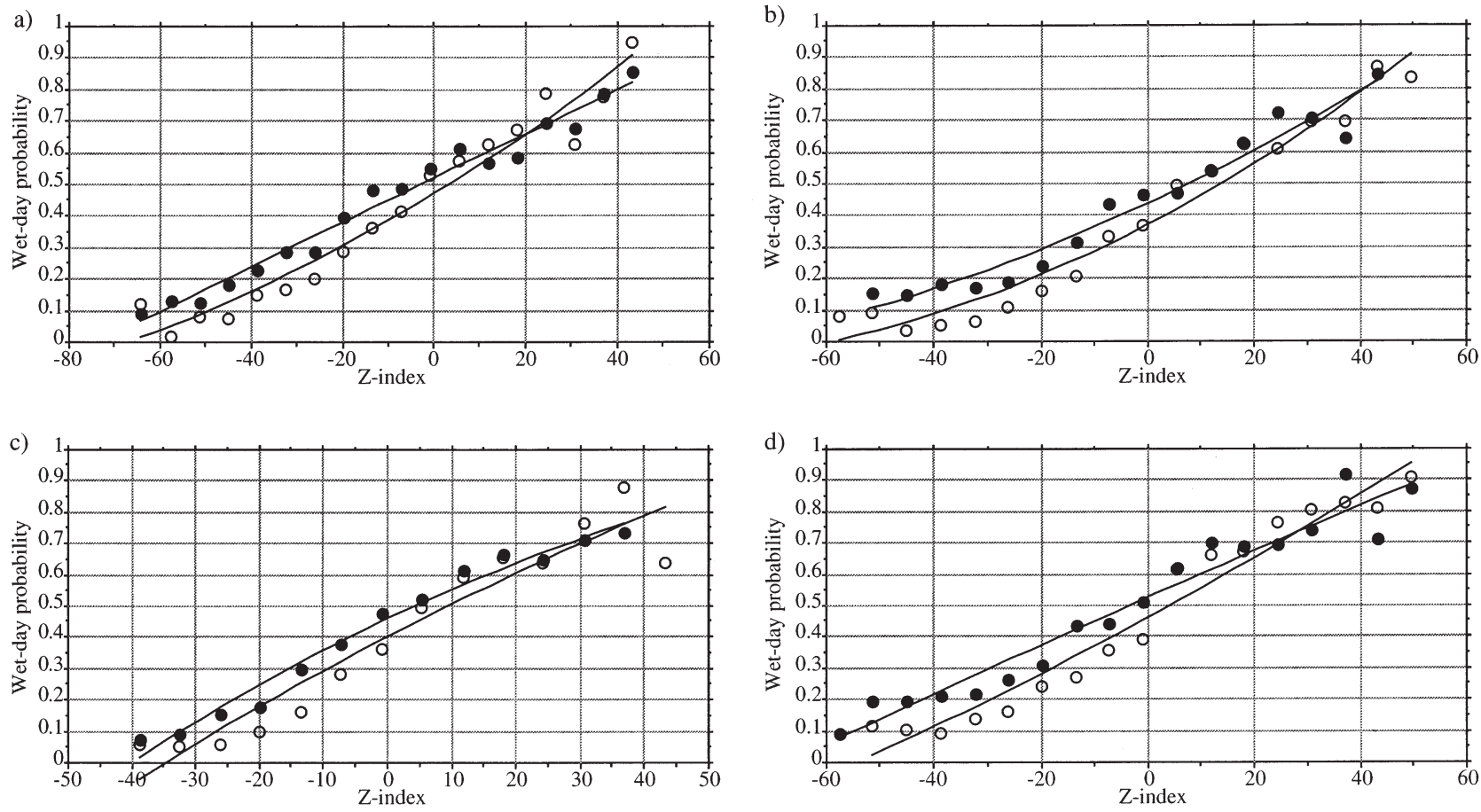

Fig. 3. Relationship between daily vorticity $(Z)$ and probability of a wet-day following a dry-day ( $\mathrm{p}_{01}$ ) at Durham (o) and Kempsford (•) in (a) DJ F, (b) MAM, (c) J J A and (d) SON, 1881-1935

lowing a dry-day are non-linearly related to the daily vorticity. Not surprisingly, higher vorticities (or cyclonicity) are associated with a higher incidence of precipitation occurrence. Although the precise shape of the curve varies between the seasons, the relationship is approximated by second-order polynomial expressions, and is remarkably similar for the 2 sites given that they are separated by a distance of $400 \mathrm{~km}$. Indeed, Conway et al. (1996) demonstrated that the relationship between the percentage of wet-days and vorticity is qualitatively similar for all 9 coherent precipitation regions of the British Isles.

Fig. 4 indicates that the polynomial transfer function is also valid for mean wet-day precipitation amounts which exhibit a non-linear increase with increasing vorticity. In this case, however, there is greater spatial heterogeneity in the shape of the curves, most notably in winter and summer. This reflects the fact that daily vorticity, calculated for a domain that covers the entire British Isles, will capture only the mesoscale forcing of daily precipitation amounts, overlooking local factors which might be of greater significance, particularly for convective precipitation events. Furthermore, the heteroscedacity of the data at the highest vorticities is attributed to the comparitively small samples used to estimate the mean wet-day amounts.

Table 2 shows the means and standard deviations of the 3 predictor variables ( $\mathrm{Z}, \mathrm{NAOI}$ and SST) by season, comparing 1881-1935 with 1936-1990. It is evident that the largest changes in the mean daily vorticity and seasonal NAOI were in winter, and for the SST anomalies in spring. These changes are reflected by increases in the mean daily wet-day amounts at Kempsford (and to a lesser extent at Durham). With the exception of Durham in summer, all seasons show an overall increase in the mean wet-day amounts, accompanied by a general increase in the standard deviation of wet-day amounts. The SST anomaly was the only predictor to show a uni-directional change in the seasonal means (albeit only a slight increase) between the 2 periods. However, a Student t-test revealed that none of the differences in the predictor means between 1881-1935 and 1936-1990 were statistically significant $(p<0.10)$.

As Table $3 a$ and $b$ indicate, the annual series of the seasonal mean wet-day amounts $(\mu)$, conditional wetday $\left(p_{11}\right)$ and conditional dry-day $\left(p_{00}\right)$ occurrences are significantly ( $p<0.05$ ) correlated with certain annual series of the seasonal NAOI and SSTs respectively. Although the NAOI is negatively correlated with all 3 precipitation processes, there are no common sets of agreement between the 2 sites or between any 2 pairs of seasons. However, the negative correlations between precipitation and the NAOI are consistent with previous analyses of surface climate variability at individual sites in northwest Europe (Hurrell 1995) and for regional averages across the British Isles (Wilby et al. 1997). Both these studies confirm the existence of neg- 

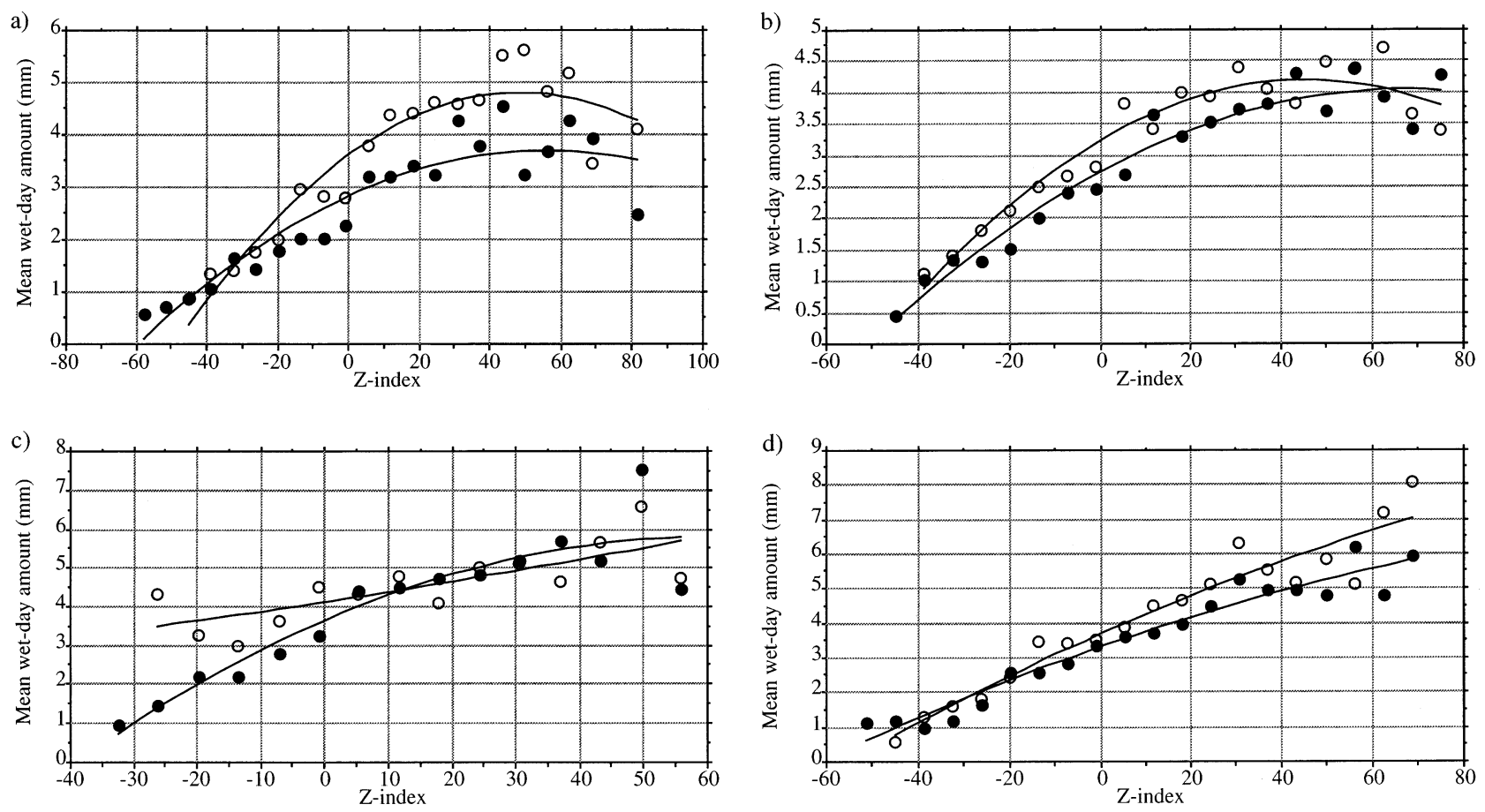

Fig. 4. Relationship between daily vorticity $(Z)$ and mean wet-day amount ( $\mu$ ) at Durham (o) and Kempsford (•) in (a) DJ F, (b) MAM, (c) J J A and (d) SON, 1881-1935

Table 2. Means and standard deviations of the predictor variables daily vorticity (Z), seasonal North Atlantic Oscillation Index (NAOI) and North Atlantic sea-surface temperature (SST) anomalies, comparing 1881-1935 with 1936-1990. Means and standard deviations of daily wet-day amounts $(\mathrm{mm})$ at Durham and Kempsford are also provided

\begin{tabular}{|c|c|c|c|c|c|c|c|c|c|}
\hline \multicolumn{2}{|l|}{ Variable } & \multicolumn{2}{|c|}{$\begin{array}{c}\text { DJ F } \\
1881-1935 \quad 1936-1990\end{array}$} & \multicolumn{2}{|c|}{$\begin{array}{c}\text { MAM } \\
1881-1935 \quad 1936-1990\end{array}$} & \multicolumn{2}{|c|}{$\frac{\mathrm{JJ} A}{1881-19351936-1990}$} & \multicolumn{2}{|c|}{\begin{tabular}{l}
\multicolumn{2}{c}{ SON } \\
$1881-1935 \quad 1936-1990$
\end{tabular}} \\
\hline Z & $\begin{array}{l}\text { Mean } \\
\text { SD }\end{array}$ & $\begin{array}{l}-4.38 \\
29.53\end{array}$ & $\begin{array}{l}-2.10 \\
30.47\end{array}$ & $\begin{array}{l}-1.46 \\
24.96\end{array}$ & $\begin{array}{l}-2.62 \\
25.72\end{array}$ & $\begin{array}{l}-0.18 \\
20.45\end{array}$ & $\begin{array}{l}-0.64 \\
20.72\end{array}$ & $\begin{array}{l}-2.32 \\
26.68\end{array}$ & $\begin{array}{l}-1.79 \\
27.29\end{array}$ \\
\hline NAOI & $\begin{array}{l}\text { Mean } \\
\text { SD }\end{array}$ & $\begin{array}{l}0.29 \\
1.80\end{array}$ & $\begin{array}{r}-0.43 \\
1.88\end{array}$ & $\begin{array}{r}-0.02 \\
1.88\end{array}$ & $\begin{array}{l}0.07 \\
1.57\end{array}$ & $\begin{array}{r}-0.16 \\
1.60\end{array}$ & $\begin{array}{l}0.15 \\
1.25\end{array}$ & $\begin{array}{l}0.16 \\
1.62\end{array}$ & $\begin{array}{l}0.30 \\
1.70\end{array}$ \\
\hline SST $^{\mathrm{a}}$ & $\begin{array}{l}\text { Mean } \\
\text { SD }\end{array}$ & $\begin{array}{r}-0.13 \\
0.25\end{array}$ & $\begin{array}{l}0.04 \\
0.31\end{array}$ & $\begin{array}{r}-0.16 \\
0.25\end{array}$ & $\begin{array}{l}0.04 \\
0.31\end{array}$ & $\begin{array}{r}-0.11 \\
0.40\end{array}$ & $\begin{array}{l}0.07 \\
0.36\end{array}$ & $\begin{array}{r}-0.07 \\
0.32\end{array}$ & $\begin{array}{l}0.07 \\
0.36\end{array}$ \\
\hline Durham & $\begin{array}{l}\text { Mean } \\
\text { SD }\end{array}$ & $\begin{array}{l}2.70 \\
3.44\end{array}$ & $\begin{array}{l}3.00 \\
4.05\end{array}$ & $\begin{array}{l}2.83 \\
3.97\end{array}$ & $\begin{array}{l}2.91 \\
4.19\end{array}$ & $\begin{array}{l}3.97 \\
5.83\end{array}$ & $\begin{array}{l}3.93 \\
5.72\end{array}$ & $\begin{array}{l}3.45 \\
5.19\end{array}$ & $\begin{array}{l}3.53 \\
5.27\end{array}$ \\
\hline Kempsford & $\begin{array}{l}\text { Mean } \\
\text { SD }\end{array}$ & $\begin{array}{l}3.69 \\
4.35\end{array}$ & $\begin{array}{l}4.17 \\
4.44\end{array}$ & $\begin{array}{l}3.41 \\
4.20\end{array}$ & $\begin{array}{l}3.85 \\
4.19\end{array}$ & $\begin{array}{l}4.41 \\
5.74\end{array}$ & $\begin{array}{l}4.78 \\
6.50\end{array}$ & $\begin{array}{l}4.21 \\
5.15\end{array}$ & $\begin{array}{l}4.74 \\
5.44\end{array}$ \\
\hline
\end{tabular}

ative correlations between seasonal or monthly precipitation totals and the seasonal NAOI, which is most pronounced for locations south of Scotland and during winter (DJ F). But, with the exception of Wall Grange, it is evident for the secondary sites that significant correlations between the seasonal NAOI and mean daily wet-day amounts occur most frequently in M AM ; significant correlations for conditional dry-day probabilities occur most frequently in JJ A (Table 3c).
In the case of the SST anomalies, only MAM conditional wet- and dry-day probabilities are significantly correlated in the same way at both key sites. However, as Fig. 5 shows for Kempsford, whilst the correlations are significant for both parameters of the renewal process in M AM, the correlation is weak and there is considerable inter-annual variability. Nonetheless, the results for Durham and Kempsford are replicated by those of the secondary sites (Table 3c). As before, the 
Table 3. Significant correlations $(<0.05)$ for the renewal $\left(p_{11}, p_{00}\right)$ and intensity $(\mu)$ processes of daily precipitation $(a)$ at Durham and Kempsford versus the North Atlantic Oscillation Index (NAOI), 1881-1995; (b) at Durham and Kempsford versus the North Atlantic sea-surface temperature (SST) anomalies ( $40^{\circ}$ to $60^{\circ} \mathrm{N}, 35^{\circ} \mathrm{W}$ to $5^{\circ} \mathrm{E}$ ), $1900-1995$; and (c) at selected sites in Central England versus the NAOI and North Atlantic SST anomalies ( $40^{\circ}$ to $60^{\circ} \mathrm{N}, 35^{\circ} \mathrm{W}$ to $\left.5^{\circ} \mathrm{E}\right), 1900-1990$

\begin{tabular}{|c|c|c|c|c|c|c|c|c|}
\hline \multirow{2}{*}{$\begin{array}{l}\text { Precipitation } \\
\text { statistic }\end{array}$} & \multicolumn{4}{|c|}{ Durham } & \multicolumn{4}{|c|}{ Kempsford } \\
\hline & DJ F & MAM & JJA & SON & DJ F & MAM & JJA & SON \\
\hline \multicolumn{9}{|c|}{ (a) Daily precipitation versus NAOI, 1881- 1995} \\
\hline$\mu$ & -0.23 & & & & & & & \\
\hline $\mathrm{p}_{11}$ & -0.22 & & & & & & -0.23 & \\
\hline $\mathrm{p}_{00}$ & & & & & & -0.25 & & -0.25 \\
\hline \multicolumn{9}{|c|}{ (b) Daily precipitation versus SST, 1900- 1995} \\
\hline$\mu$ & & & & & & +0.30 & & \\
\hline$p_{11}$ & & -0.29 & & & -0.40 & -0.33 & -0.25 & \\
\hline $\mathrm{p}_{00}$ & & +0.24 & & & & +0.44 & +0.32 & \\
\hline \multirow{2}{*}{$\begin{array}{l}\text { Precipitation } \\
\text { statistic }\end{array}$} & \multicolumn{4}{|c|}{ NAOI } & \multicolumn{4}{|c|}{ SST } \\
\hline & DJ F & MAM & JJA & SON & DJ F & MAM & JJA & SON \\
\hline \multicolumn{9}{|c|}{$\begin{array}{l}\text { (c) Daily precipitation versus NAOI and SST, 1900-1990 } \\
\text { Cambridge }\end{array}$} \\
\hline$\mu$ & & -0.32 & & & & +0.18 & & \\
\hline $\mathrm{p}_{11}$ & & & & & -0.21 & -0.33 & & -0.24 \\
\hline $\mathrm{p}_{00}$ & & & & -0.20 & +0.24 & +0.48 & +0.23 & \\
\hline \multicolumn{9}{|l|}{ Derby } \\
\hline$\mu$ & & -0.24 & & & -0.23 & & & -0.26 \\
\hline$p_{11}$ & & & & & -0.43 & -0.34 & & \\
\hline $\mathrm{p}_{00}$ & & -0.20 & & -0.34 & +0.19 & +0.43 & +0.35 & \\
\hline \multicolumn{9}{|l|}{ Norwich } \\
\hline$\mu$ & & -0.27 & & & & & & \\
\hline $\mathrm{p}_{11}$ & & & & & & -0.33 & & \\
\hline $\mathrm{p}_{00}$ & & & -0.21 & & & +0.33 & +0.26 & \\
\hline \multicolumn{9}{|l|}{ Sandringham } \\
\hline$\mu$ & & -0.20 & & & & & & \\
\hline $\mathrm{p}_{11}$ & & & & & & -0.22 & & \\
\hline $\mathrm{p}_{00}$ & & & -0.21 & & & +0.33 & & \\
\hline \multicolumn{9}{|l|}{ Wall Grange } \\
\hline$\mu$ & & & & & & & & \\
\hline $\mathrm{p}_{11}$ & +0.22 & & & & -0.24 & -0.37 & -0.24 & -0.20 \\
\hline $\mathrm{p}_{00}$ & & -0.34 & -0.31 & & -0.25 & +0.35 & +0.35 & \\
\hline
\end{tabular}

renewal processes, $\mathrm{p}_{11}$ and $\mathrm{p}_{00}$, are significantly correlated at all sites with the SST anomalies in MAM. Similarly, $\mathrm{p}_{00}$ is positively correlated with the SST anomalies at all sites except Durham and Sandringham in JJA. These findings are consistent with the positive correlations found between summer SSTs and summer Central England Temperatures (Colman 1997), given that longer summer dry spells generally herald higher summer temperatures.

High correlation scores from empirical predictorpredictand relationships can often result either from a trend in the data or from the persistence of anomalies in the independent variable. Significant $(p<0.05)$ trends in mean SSTs were detected in 4 series: J FM, FMA, NDJ and DJ F. This suggests that amongst all the SST correlation results reported in Table $3 b, c$, only those for DJF may have been biased by the trend in SSTs. The seasonal SST series were also investigated for persistence by deriving correlation coefficients between the current and preceeding 4 seasons. For example, Table 4 reveals that SSTs in MAM are highly correlated ( $r=+0.78$ ) with SSTs in the preceeding DJ F. The results indicate that the significant correlations between precipitation parameters and SSTs in MAM (Table 3b, c) could be partly explained by the persistence of the SST anomalies between winter and spring. This outcome is also consistent with Colman's (1997) assertion that a very persistent wavetrain-like SST anomaly pattern exists in the North Atlantic between J anuary-February and April-May.

From these preliminary analyses, it is reasonable to expect that the inclusion of the NAOI or SST anomalies as 

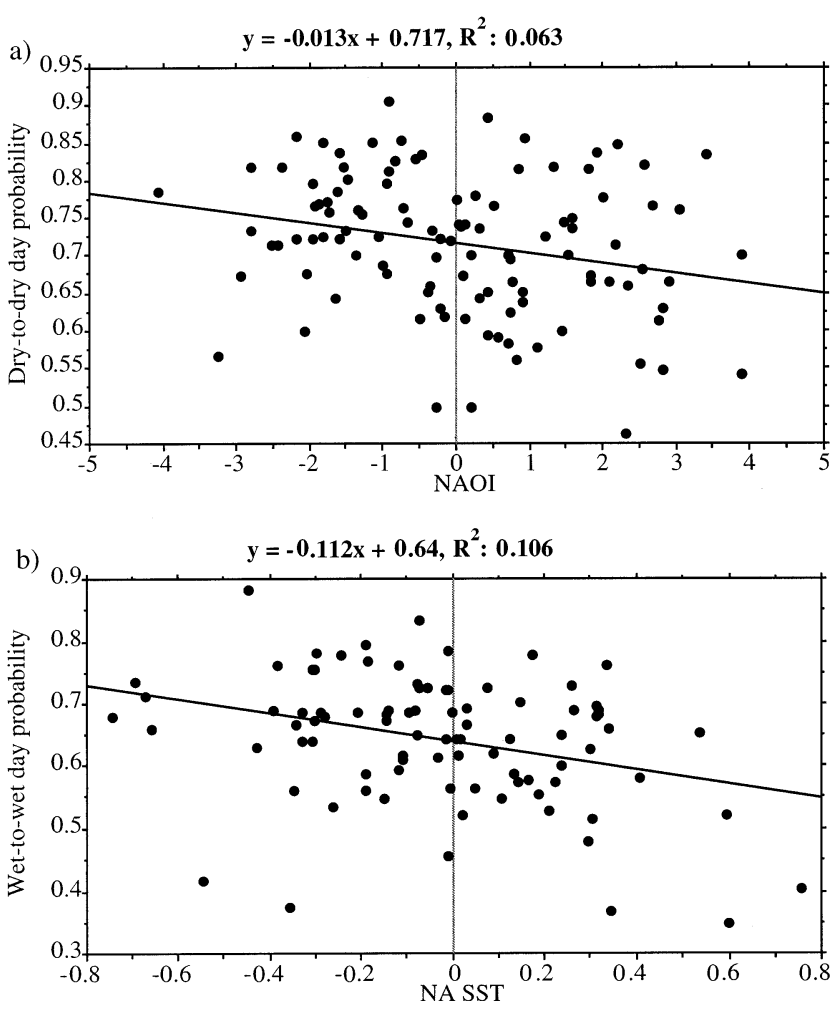

Fig. 5. Relationship (a) between the conditional dry-day probability $\left(p_{00}\right)$ at Kempsford and the North Atlantic Oscillation Index (NAOI) in MAM, 1881-1990; and (b) between the conditional wet-day probability $\left(\mathrm{p}_{11}\right)$ at Kempsford and North Atlantic sea-surface temperature (NA SST) anomalies in MAM, 1901-1990

predictors in the vorticity-based downscaling should yield modest improvements in monthly precipitation statistics on a relatively limited number of occasions: most notably in MAM when either the NAOI or SSTs are employed. The following sections describe the calibration and validation of 3 statistical downscaling models used to quantify the relative contribution of $\mathrm{Z}, \mathrm{NAOI}$ and SSTs to downscaled monthly precipitation variability.

\section{DAILY PRECIPITATION MODELS}

This section presents 3 alternative models for statistically downscaling daily precipitation series using combinations of airflow and teleconnection indices. In each case, the models were calibrated using regional predictors (Z, NAOI, SSTs) and station precipitation data at Kempsford and Durham for each climatological season (i.e. DJF, MAM, JJA, SON) in the period 1881-1935. For the validation period 1936-1990, the models were forced using the regional predictors only, and the downscaled daily precipitation at each site was compared with observed data, again on a seasonal basis. Although standard climatological seasons were
Table 4. Correlations between current North Atlantic SSTs and SSTs for the previous 4 seasons, 1901-1990. All correlations are significant $(p<0.05)$

\begin{tabular}{lllll}
\hline \multirow{2}{*}{$\begin{array}{l}\text { Previous } \\
\text { season }\end{array}$} & DJ F & \multicolumn{3}{c}{ Current season } \\
& & MAM & JJA & SON \\
\hline DJ F & +0.58 & +0.78 & +0.53 & +0.56 \\
MAM & +0.64 & +0.60 & +0.68 & +0.68 \\
J J & +0.57 & +0.62 & +0.41 & +0.72 \\
SON & +0.75 & +0.60 & +0.40 & +0.50 \\
& & & & \\
\hline
\end{tabular}

employed throughout, it is acknowledged that downscaling results can be sensitive to season definitions (Winkler et al. 1997). Nonetheless, the inter-season variations in mean wet-day amounts shown in Table 2 , as well as the subtle differences in the polynomial curves (shown in Figs. 2 to 4) suggest that the chosen seasons are legitimate. However, it is conceded that season may be acting as a hidden variable and that more parsimonious models could be developed.

In Models 2 and 3, the low-frequency variability is treated additively due to the assumed linear relationships between NAOI or SSTs and each precipitation parameter (see Fig. 5). The alternative approach to modelling low-frequency variability (as described by Katz \& Parlange 1996) was not employed because of the arbitrary choices involved in stratifying the parameters by the conditioning variable.

\subsection{Model 1: vorticity only}

Variants of the vorticity-only model have been previously described by Conway et al. (1996), Pilling et al. (1998), and by Wilby et al. (1998). As shown in Figs. 2 to 4 , the renewal $\left(p_{01}\right.$ and $p_{11}$ ) and intensity $(\mu)$ processes for a given season may be modelled using second-order polynomial expressions

$$
\begin{aligned}
p_{01} & =a_{0}+a_{1} z+a_{2} z^{2} \\
p_{11} & =b_{0}+b_{1} z+b_{2} z^{2} \\
\mu & =c_{0}+c_{1} z+c_{2} z^{2}
\end{aligned}
$$

Daily vorticity values (whether observed or derived from GCM output) are used to determine the probability of precipitation using Eq. (1) if the previous day was dry and Eq. (2) if the previous day was wet. Precipitation occurs on the current day if $r_{1} \leq p_{11}$ (or $p_{01}$ if the previous day was dry) where $r_{1}$ is a uniformly distributed random number $\left(0 \leq r_{1} \leq 1\right)$. If it is determined that precipitation occurs, the mean intensity $(\mu)$ for a given vorticity is calculated using Eq. (3). The actual daily precipitation amount $(\mathrm{R})$ for any given day is modelled stochastically using 


$$
R=-\varnothing \mu \ln \left(r_{2}\right)
$$

where $r_{2}$ is a second uniformly distributed random number $\left(0<r_{2} \leq 1\right)$ and $\varnothing$ is a random scaling factor used to inflate the variance of $\mathrm{R}$ to accord better with observations (as in Hay et al. 1991). If the mean of $\varnothing$ is 1 , the equality of $\mu$ and $R$ is preserved. Without this term the variance of observed daily precipitation amounts modelled using the exponential distribution is significantly underestimated.

\subsection{Model 2: vorticity and North Atlantic Oscillation Index}

Model 2 is identical to Model 1 in all respects except that Eqs. (1) to (3) become

$$
\begin{aligned}
p_{01} & =a_{0}+a_{1} z+a_{2} z^{2}+a_{3} \text { NAOI } \\
p_{11} & =b_{0}+b_{1} z+b_{2} z^{2}+b_{3} \text { NAOI } \\
\mu & =c_{0}+c_{1} Z+c_{2} z^{2}+c_{3} \text { NAOI }
\end{aligned}
$$

where NAOI is the seasonal North A tlantic Oscillation Index (Hurrell 1995). The revised equations thereby assume the same long-term means for the renewal and intensity processes (i.e. $a_{0}, b_{0}$ and $c_{0}$ ) but add low-frequency variability associated with the NAOI to the daily variability due to vorticity.

\subsection{Model 3: vorticity and N orth A tlantic sea-surface temperature anomalies}

M odel 3 is identical to M odel 1 in all respects except that Eqs. (1) to (3) become

$$
\begin{aligned}
p_{01} & =a_{0}+a_{1} z+a_{2} z^{2}+a_{3} \text { SST } \\
p_{11} & =b_{0}+b_{1} z+b_{2} z^{2}+b_{3} \text { SST } \\
\mu & =c_{0}+c_{1} z+c_{2} z^{2}+c_{3} \text { SST }
\end{aligned}
$$

where SST is the seasonal North Atlantic sea-surface temperature anomalies (for the region $40^{\circ}$ to $60^{\circ} \mathrm{N}, 35^{\circ}$ to $5^{\circ} \mathrm{E}$ ) from the corrected GISST data set (Folland \& Parker 1995). The revised equations thereby assume the same long-term means for the renewal and amount processes (i.e. $a_{0}, b_{0}$ and $c_{0}$ ) but add low-frequency variability associated with SST anomalies to the daily variability due to vorticity.

The structures of Models 2 and 3 assume that seasonal time series of vorticity were uncorrelated with the NAOI and SST anomalies. Whilst annual means of the NAOI and Z were insignificantly correlated $(r=$ -0.01 ), there was a weak negative correlation between annual mean SST anomalies and $Z(r=-0.33)$. This will slightly inflate the variance of $\mathrm{p}_{11}$ and $\mathrm{p}_{01}$, and reduce the variance of $\mu$ in Model 3 .

\section{MODEL RESULTS}

Table 5 presents the validation results of the precipitation downscaling using observed predictor variables (Z, NAOI and SST) for the period 1936-1990 and the 3 models of daily precipitation at Durham and Kempsford. Note that the downscaled precipitation statistics shown in Table 5 are mean results obtained from onehundred, $55 \mathrm{yr}$ stochastic simulations of the 3 models. For each precipitation statistic the best model result is highlighted in bold.

Overall, Model 3 yields the most accurate precipitation statistics on $56 \%$ of occasions for Kempsford and $54 \%$ for Durham. The corresponding figures for Model 2 are 24 and $16 \%$ respectively, and for Model 1 20 and $30 \%$ respectively. Although M odel 3 produced superior results compared with Models 1 and 2 , on the majority of occasions, the improvements were modest, generally less than a $10 \%$ gain when compared with the observed statistics. However, there were a few notable exceptions, namely, the improved downscaling by Model 3 of the standard deviations of dry-spell lengths and the standard deviation of the monthly frequency of wet-days at Kempsford. For all seasons, with the possible exception of SON (Table 5d), M odel 3 significantly improved the downscaling of these precipitation statistics.

Although Models 2 and 3 yielded only marginal gains in the simulation of most precipitation statistics listed in Table 5, it is pertinent that these 2 models produced superior results to M odel 1 on 24 out of 32 occasions for the low-frequency (i.e. monthly) diagnostics. Therefore, it is possible to conclude that the inclusion of low-frequency predictors does slightly enhance simulations of low-frequency precipitation variability at the 2 sites. Overall, the greater improvement in lowfrequency diagnostics occurred at Kempsford, reflecting the greater number and strength of significant correlations between daily precipitation processes and the seasonal NAOI or SSTs at this site (Table 3a, b). Both predictors are significantly correlated with parameters which govern the renewal process (i.e. $p_{11}$ and $\left.p_{00}\right)$, a connection that is manifested in the results in Table 5.

From Table 5 it is also evident that Models 2 and 3 produce similar results to M odel 1 in terms of the daily precipitation statistics. With the exception of Durham in DJF and JJA, all 3 downscaling models underestimate the mean wet-day amounts. This is a consequence of the relative dryness of the calibration period compared with the validation period (cf. Table 2), and 
Table 5. Validation of models using daily and monthly precipitation statistics: (a) DJ F; (b) MAM ; (c) JJ A; and (d) SON. For each precipitation statistic the best model result is given in bold

\begin{tabular}{|c|c|c|c|c|c|c|c|c|c|}
\hline \multirow[t]{2}{*}{ Precipitation statistic } & & \multicolumn{4}{|c|}{ Durham 1936-1990 } & \multicolumn{4}{|c|}{ Kempsford 1936-1990 } \\
\hline & & Observed & Model 1 & Model 2 & Model 3 & Observed & Model 1 & Model 2 & Model 3 \\
\hline \multicolumn{10}{|l|}{ (a) DJ F } \\
\hline \multirow[t]{2}{*}{ Wet-day (mm) } & Mean & 3.00 & 3.00 & 2.98 & 3.01 & 4.17 & 3.83 & 3.90 & 3.89 \\
\hline & $\mathrm{SD}$ & 4.05 & 4.24 & 4.22 & 4.27 & 4.44 & 5.45 & 5.55 & 5.54 \\
\hline \multirow[t]{2}{*}{ Wet spell (d) } & Mean & 3.62 & 3.01 & 3.07 & 3.03 & 2.69 & 2.93 & 2.91 & 2.96 \\
\hline & SD & 3.50 & 2.56 & 2.66 & 2.62 & 2.56 & 2.59 & 2.60 & 2.71 \\
\hline \multirow[t]{2}{*}{ Dry spell (d) } & Mean & 2.41 & 2.21 & 2.22 & 2.26 & 3.17 & 2.54 & 2.57 & 2.65 \\
\hline & $\mathrm{SD}$ & 2.06 & 1.79 & 1.80 & 1.89 & 4.48 & 2.23 & 2.29 & 2.49 \\
\hline \multirow[t]{2}{*}{ Monthly total (mm) } & Mean & 54.4 & 52.6 & 52.6 & 52.4 & 57.6 & 62.6 & 63.1 & 62.5 \\
\hline & SD & 31.6 & 23.3 & 23.3 & 23.8 & 33.0 & 30.1 & 30.6 & 31.8 \\
\hline \multirow[t]{2}{*}{ Monthly no. of wet-days } & Mean & 18.07 & 17.54 & 17.68 & 17.43 & 13.81 & 16.15 & 16.02 & 15.91 \\
\hline & SD & 4.77 & 3.77 & 3.84 & 4.03 & 5.43 & 4.14 & 4.22 & 4.68 \\
\hline \multicolumn{10}{|l|}{ (b) MAM } \\
\hline \multirow{2}{*}{ Wet-day (mm) } & Mean & 2.91 & 2.74 & 2.71 & 2.72 & 3.85 & 3.33 & 3.32 & 3.35 \\
\hline & SD & 4.19 & 3.85 & 3.80 & 3.82 & 4.19 & 4.51 & 4.49 & 4.52 \\
\hline \multirow[t]{2}{*}{ Wet spell (d) } & Mean & 3.17 & 2.95 & 2.94 & 2.95 & 2.75 & 2.67 & 2.69 & 2.71 \\
\hline & SD & 3.18 & 2.51 & 2.50 & 2.50 & 2.29 & 2.22 & 2.25 & 2.28 \\
\hline \multirow[t]{2}{*}{ Dry spell (d) } & Mean & 3.00 & 2.65 & 2.64 & 2.62 & 4.03 & 3.17 & 3.18 & 3.29 \\
\hline & SD & 3.10 & 2.30 & 2.27 & 2.25 & 5.70 & 2.96 & 2.99 & 3.39 \\
\hline \multirow[t]{2}{*}{ M onthly total (mm) } & Mean & 45.8 & 43.9 & 43.6 & 43.9 & 47.9 & 46.4 & 46.3 & 46.1 \\
\hline & SD & 26.9 & 21.1 & 20.9 & 21.3 & 28.0 & 24.1 & 23.7 & 23.9 \\
\hline \multirow[t]{2}{*}{ M onthly no. of wet-days } & Mean & 15.75 & 16.04 & 16.06 & 16.15 & 12.44 & 13.79 & 13.83 & 13.63 \\
\hline & $\mathrm{SD}$ & 5.35 & 4.13 & 4.08 & 4.04 & 5.29 & 4.29 & 4.36 & 4.73 \\
\hline \multicolumn{10}{|l|}{ (c) JJA } \\
\hline \multirow[t]{2}{*}{ Wet-day (mm) } & Mean & 3.93 & 3.94 & 3.93 & 3.95 & 4.78 & 4.33 & 4.34 & 4.32 \\
\hline & SD & 5.72 & 5.44 & 5.46 & 5.49 & 6.50 & 5.68 & 5.66 & 5.62 \\
\hline \multirow[t]{2}{*}{ Wet spell $(d)$} & Mean & 2.86 & 2.64 & 2.64 & 2.66 & 2.32 & 2.44 & 2.44 & 2.45 \\
\hline & SD & 2.54 & 2.20 & 2.19 & 2.20 & 1.82 & 2.00 & 2.01 & 2.00 \\
\hline \multirow[t]{2}{*}{ Dry spell (d) } & Mean & 3.07 & 2.61 & 2.61 & 2.68 & 3.93 & 3.04 & 3.02 & 3.14 \\
\hline & SD & 3.26 & 2.24 & 2.27 & 2.36 & 5.58 & 2.79 & 2.79 & 3.03 \\
\hline \multirow[t]{2}{*}{ Monthly total (mm) } & Mean & 58.1 & 60.3 & 60.3 & 59.9 & 54.4 & 58.7 & 59.0 & 57.7 \\
\hline & $\mathrm{SD}$ & 32.6 & 28.2 & 28.6 & 28.7 & 34.1 & 28.3 & 28.6 & 28.5 \\
\hline \multirow[t]{2}{*}{ Monthly no. of wet-days } & Mean & 14.80 & 15.32 & 15.33 & 15.17 & 11.37 & 13.44 & 13.47 & 13.21 \\
\hline & SD & 5.06 & 3.92 & 3.93 & 4.00 & 5.08 & 4.05 & 4.05 & 4.25 \\
\hline (d) SON & & & & & & & & & \\
\hline Wet-day (mm) & Mean & 3.53 & 3.44 & 3.44 & 3.41 & 4.74 & 4.12 & 4.12 & \\
\hline & SD & 5.27 & 4.85 & 4.85 & 4.83 & 5.44 & 5.71 & 5.68 & 5.74 \\
\hline Wet spell (d) & Mean & 3.22 & 3.14 & 3.14 & 3.15 & 2.70 & 2.69 & 2.73 & 2.72 \\
\hline & $\mathrm{SD}$ & 3.02 & 2.65 & 2.65 & 2.66 & 2.47 & 2.28 & 2.34 & 2.30 \\
\hline Dry spell (d) & Mean & 2.63 & 2.18 & 2.17 & 2.19 & 3.52 & 2.54 & 2.54 & 2.60 \\
\hline & SD & 2.55 & 1.77 & 1.76 & 1.77 & 4.81 & 2.21 & 2.25 & 2.32 \\
\hline M onthly total (mm) & Mean & 58.9 & 62.0 & 61.9 & 61.4 & 62.4 & 64.7 & 65.1 & 65.0 \\
\hline & SD & 35.8 & 26.7 & 26.5 & 27.3 & 37.4 & 30.6 & 31.0 & 30.7 \\
\hline Monthly no. of wet-days & Mean & 16.70 & 17.98 & 18.02 & 18.01 & 13.16 & 15.53 & 15.65 & 15.45 \\
\hline & SD & 4.84 & 3.74 & 3.72 & 3.77 & 5.35 & 3.98 & 4.12 & 4.04 \\
\hline
\end{tabular}

of the fact that the assumed exponential distribution of wet-day amounts tends to underestimate the magnitude of extreme events. Furthermore, the empirical relationships in Eqs. (5) to (10) are assumed to be stationary when, in practice, the relationships between teleconnection indices and surface climate variables are known to vary through time (e.g. Nicholls et al. 1996). Such effects are not included in the present models; therefore, any changes to downscaled precipitation such as mean wet-day amounts or spell-lengths are the result of differences in the mean Z, NAOI or SSTs between 1881-1935 and 1936-1990 (Table 2). 


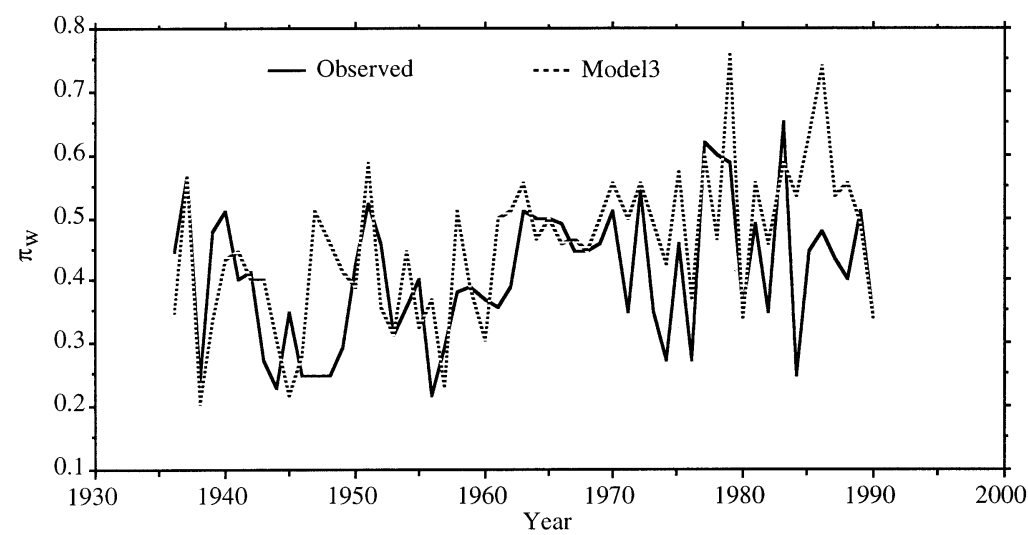

Fig. 6. A comparison of the observed annual series of the unconditional wet-day probability $\left(\pi_{w}\right)$ at Kempsford in MAM with the series produced by statistically downscaling daily vorticity and seasonal SST anomalies using Model 3, 1936-1990

The underestimation of the standard deviations of spell lengths by Models 2 and 3 suggests that the modest changes in the means of the low-frequency predictors provide only a partial explanation for inter-decadal variability in single-site precipitation diagnostics.

Of further interest, is the extent to which Models 2 and 3 are better able to reproduce the time-series attributes of the daily precipitation at Durham and Kempsford. By way of an example, Fig. 6 compares the observed annual series of the unconditional wet-day probabilities $\left(\pi_{\mathrm{w}}\right)$ at Kempsford in MAM, with the series produced by daily vorticity and seasonal SST anomaly forcing (i.e. Model 3). Note that the downscaled time series is a single realisation produced by the stochastic processes in Model 3. Note also that, although the results are for the validation period 1936-1990, the comparison in Fig. 6 is probably an optimal-case scenario given the strength of the correlations between SST anomalies and precipitation parameters at Kempsford during the chosen season (cf. Table 3b). Nonetheless, the regional forcing produces an annual series for $\pi_{w}$ that is significantly $(p=0.0001)$ correlated $(r=+0.64)$ with observed data. In comparison, the correlations for the $\pi_{\mathrm{w}}$ series produced by Model $1(r=+0.61)$ and Model $2(r=+0.44)$ are marginally weaker, whereas the correlations between observed and downscaled $\mu$ are statistically insignificant for all 3 models. Similar results were obtained for the downscaled annual series of $\pi_{w}$ and $\mu$ for MAM at Durham. At this site, observed $\mu$-series were weakly correlated $(r=+0.33)$ with the downscaled series of Model 2, but insignificantly correlated with the results of Models 1 and 3. Once again, the observed $\pi_{\mathrm{w}}$ series were significantly correlated with the downscaled series of all 3 models, but M odel 3 was, in this case, by far the most proficient $(r=+0.54)$.
The results of the time-series analyses of $\pi_{\mathrm{w}}$ and $\mu$ suggest that the inclusion of seasonal predictors in downscaling models can yield modest advances in the description of inter-annual variability of key precipitation parameters at individual sites relative to less sophisticated vorticity-only models. However, these gains are likely to be restricted to particular seasons and geographic locations that are determined by the dominant mode(s) of the regional forcing. In the case of both the NAOI and SST anomalies, the optimal season is MAM (Table $3 \mathrm{~b}, \mathrm{c})$, and the region central England. However, further sites should be investigated to assess the generality of these results. Furthermore, stronger correlations between observed and downscaled time series would be expected for area-average, as opposed to single-site, precipitation (as in Wilby et al. 1995).

\section{DISCUSSION AND CONCLUSIONS}

Non-stationary predictor-predictand relationships are a major obstacle confounding the application of statistical downscaling models to future climates (Wilby 1997). However, such non-stationarity may, in fact, be an artefact of the failure of many downscaling models to incorporate appropriate low-frequency predictor variables. The present study has explored the possibility of using variables that characterise both the daily and monthly variability of daily precipitation at selected sites in the British Isles.

Accordingly, 3 statistical downscaling models were calibrated by regressing parameters describing the daily precipitation at the sites of Durham and Kempsford, UK, against regional climate predictors. M odel 1 employed only 1 predictor, the daily vorticity obtained from daily grid-point mean-sea-level pressure over the British Isles. Model 2 employed both daily vorticity and seasonal NAOI as predictors. Finally, Model 3 employed daily vorticity and seasonal North Atlantic SST anomalies as predictors. All 3 models were validated using daily and monthly precipitation statistics at the same stations for the period 1936-1990. Although M odels 2 and 3 yielded improvements in the downscaling of the low-frequency precipitation diagnostics, the enhancements were modest relative to Model 1 (the vorticity-only model).

This result might have been expected a priori given the relatively weak correlations of the daily precipitation renewal and intensity processes with the low- 

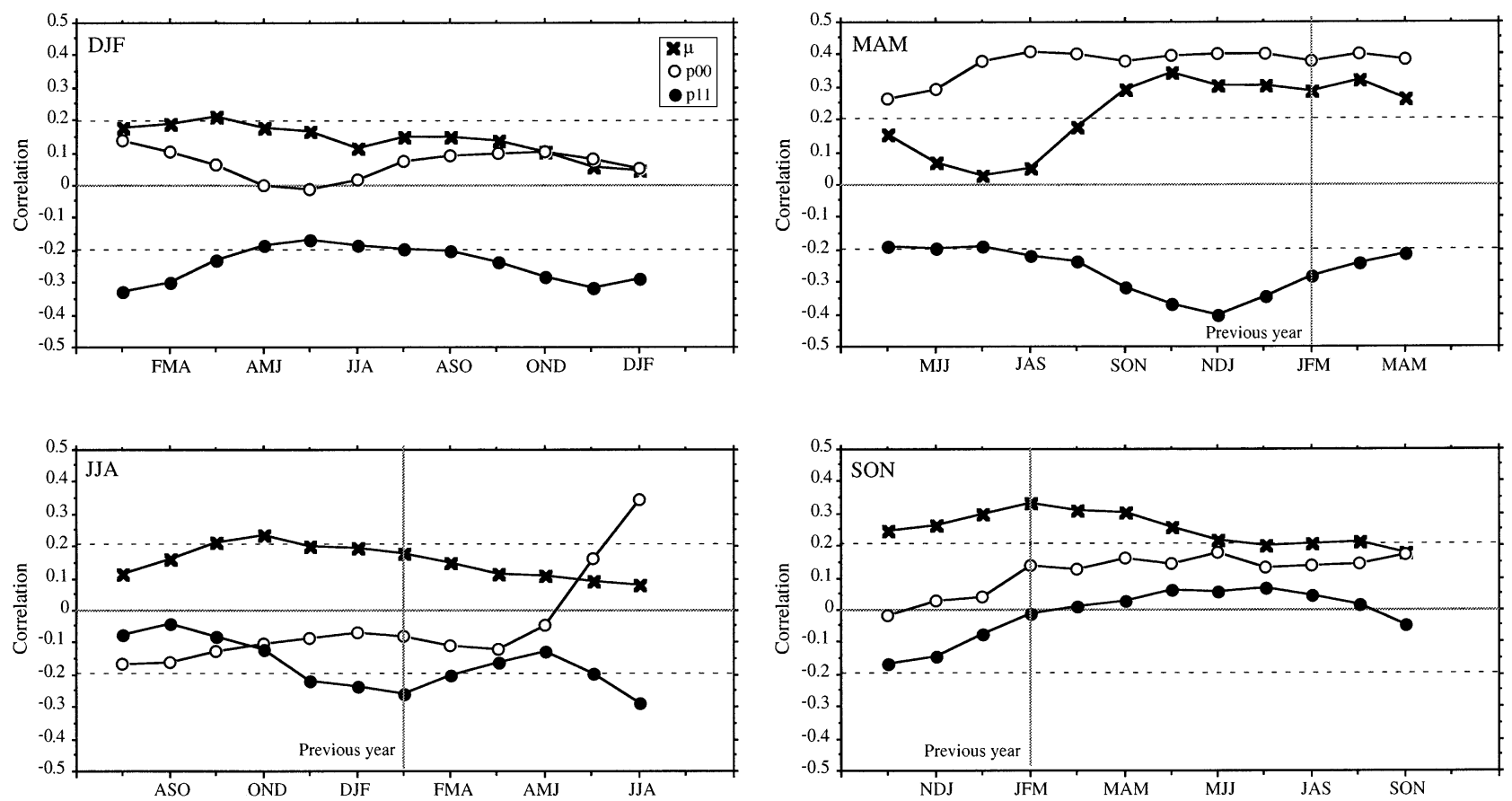

Fig. 7. Correlations between the mean wet-day amount $(\mu)$, conditional wet-day probability $\left(p_{11}\right)$ and the conditional dry-day probability $\left(\mathrm{p}_{00}\right)$ at Kempsford versus N orth Atlantic SST anomalies, 1901-1990. For each climatological season the annual time series of the precipitation parameters were correlated with antecedent values of the 3 mo mean SSTs. For example, the M AM $p_{11}$ parameter is most strongly (negatively) correlated with the preceeding NDJ mean SSTs. Thin dashed lines denote correlations significant at the $p<0.05$ level

frequency predictors (NAOI and SST). However, from the preceding results it is clear that SSTs had marginally more explanatory power than the NAOI, a not unsurprising outcome given the dependency of the NAOI on SSTs (Hurrell 1995). Furthermore, Colman (1997) demonstrated a significant correlation between North Atlantic SST anomalies in winter (J anuaryFebruary) and the subsequent summer (J uly-A ugust) Central England Temperatures but the correlation with the NAOI was much lower. The same study also revealed that the correlation skill of SSTs for rainfall in England and Wales was insignificant at the $p<0.05$ level.

Although the present study did not include laggedSST predictors in the downscaling, stronger correlations may be found between certain precipitation parameters $\left(\mu, p_{11}, p_{00}\right)$ and antecedent SSTs. For example, Fig. 7 shows that the MAM $p_{11}$ parameter at Kempsford was most strongly (negatively) correlated with the preceeding NDJ mean SSTs. Similarly, Fig. 8 reveals that significant negative correlations existed between $\mathrm{p}_{00}$ (SON) at Durham and preceding FMA SST anomalies, and between $p_{00}(J) A$ ) and preceding ASO SSTs. In the latter case, there was a marked shift from negative correlations between $p_{00}$ and lagged SSTs to a positive correlation with concurrent SST anomalies. Comparing Figs. $7 \& 8$ it is evident that the results obtained from the 2 sites are broadly consistent, with the notable exceptions of MAM $\mu, J J A p_{11}$ and SON $p_{00}$. Overall, however, the majority of the lagged correlations at both Durham and Kempsford were insignificant at the $p<0.05$ level such that, in most cases, the non-lagged (i.e. concurrent) seasonal SSTs provide a reasonable approximation of the maximum significant correlations. Clearly, further research is required to determine the extent of the spatial dependency in the teleconnections, and to define the optimum lag-interval for the precipitation parameters of a given site and season.

Nonetheless, the interim model results suggest that there may be some merit in using the N orth A tlantic SST series as a downscaling predictor variable for sites in the UK. To date, however, there has been an almost exclusive use of atmospheric circulation indices or weather classification systems for precipitation downscaling. Additional research is required to determine which, if any, other low-frequency predictor variables should be incorporated in statistical downscaling models for Europe. For example, there is tentative evidence to suggest that luni-solar forcing may modulate inter-decadal variations in extreme hourly rainfalls in the UK (e.g. M ay \& Hitch 1989) or signals in North Atlantic tropical cyclone occurrence (e.g. Currie 1996). Alternatively, the Southern Oscillation Index (SOI) has also been shown to correlate weakly with winter rainfall totals over the British Isles 

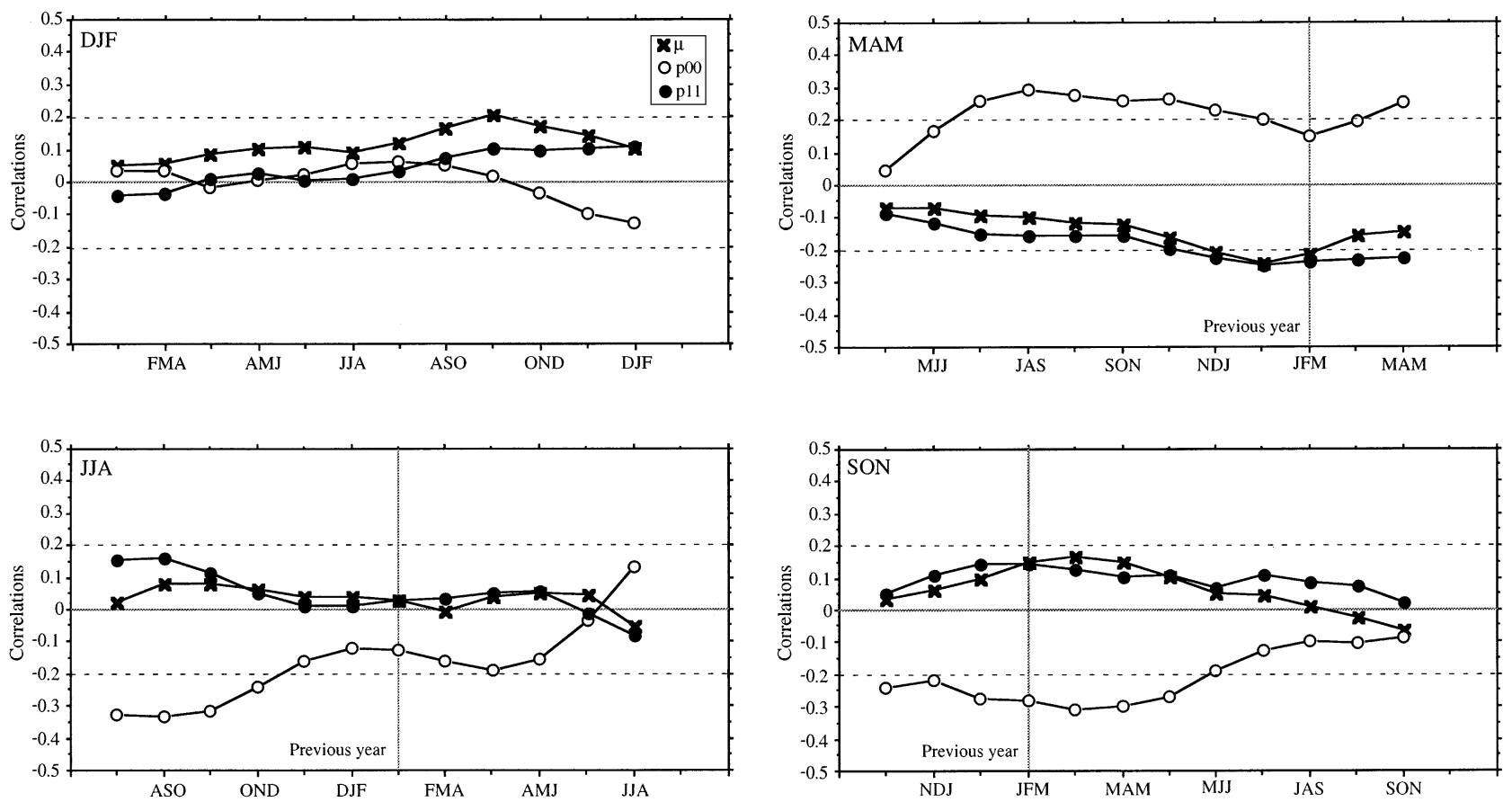

Fig. 8. Correlations between the mean wet-day amount $(\mu)$, conditional wet-day probability $\left(p_{11}\right)$ and the conditional dry-day probability $\left(\mathrm{p}_{00}\right)$ at Durham versus North Atlantic SST anomalies, 1901-1990. For each climatological season the annual time series of the precipitation parameters were correlated with antecedent values of the 3 mo mean SSTs. Thin dashed lines denote correlations significant at the $p<0.05$ level

(Wilby 1993). Clearly, there is also a need to establish the optimum form of the mathematical transfer functions (i.e. whether linear, non-linear, multi-variate, etc.), as well as the most parsimonious combination of (uncorrelated) predictor variables.

Ideally, physically explainable variables such as atmospheric humidity should be used in preference to correlated teleconnection indices as a means of downscaling low-frequency precipitation variations (Hewitson pers. comm.). Ideally, the downscaling should employ variables representing the primary forcing on the predictand, at the appropriate temporal and spatial resolution of the processes involved. Unfortunately, most instrumental records are simply too short to adequately sample inter-decadal climate variability, and therefore there is a need to make recourse to proxy variables such as SSTs or the NAOI for which longer ( $\geq 100 \mathrm{yr}$ ) records are available. Until variables representing primary atmospheric dynamics become available there is always a danger that the use of teleconnection indices will introduce additional forms of non-stationarity into the downscaling (see below). In the meantime, links between teleconnection indices and European climate, expressed in terms of changes in the frequency of key circulation patterns (e.g. Fraedrich \& M uller 1992, Wilby 1993), provide a plausible basis for downscaling.
Further explanations for the rather limited gains in the downscaling of the low-frequency precipitation statistics using the present set of predictors may be that daily station data are of too high spatial and temporal resolution to capture this regional-scale forcing. In other words, changes in local-forcing factors may be of greater significance to the inter-decadal variability of daily precipitation renewal and intensity processes at Durham and Kempsford. Hence, spatial averaging of multiple station data could reduce the noise component and increase the signal in the precipitation time series. Alternatively, the geographic location of the 2 primary sites relative to the dominant centres of airflow forcing may predispose weak correlations. For example, Wigley \& J ones (1987) demonstrated that the strongest correlations between westerly airflows and monthly precipitation are in NW England. Similarly, analyses of the North Atlantic Oscillation, and its affect on regional rainfall variability across the British Isles, indicate that the strongest correlations between seasonal rainfall totals and the NAOI occur in northern Scotland (positive correlation) and central England (negative correlation) (Wilby et al. 1997). These findings are endorsed, to a certain extent, by the correlation results obtained for the secondary sites in central and eastern England (Table 3c). Therefore, low-frequency variations in precipitation renewal and intensity processes due to air- 
flow and/or teleconnection forcing(s) are expected to have a greater impact on downscaled daily precipitation at stations located in these regions.
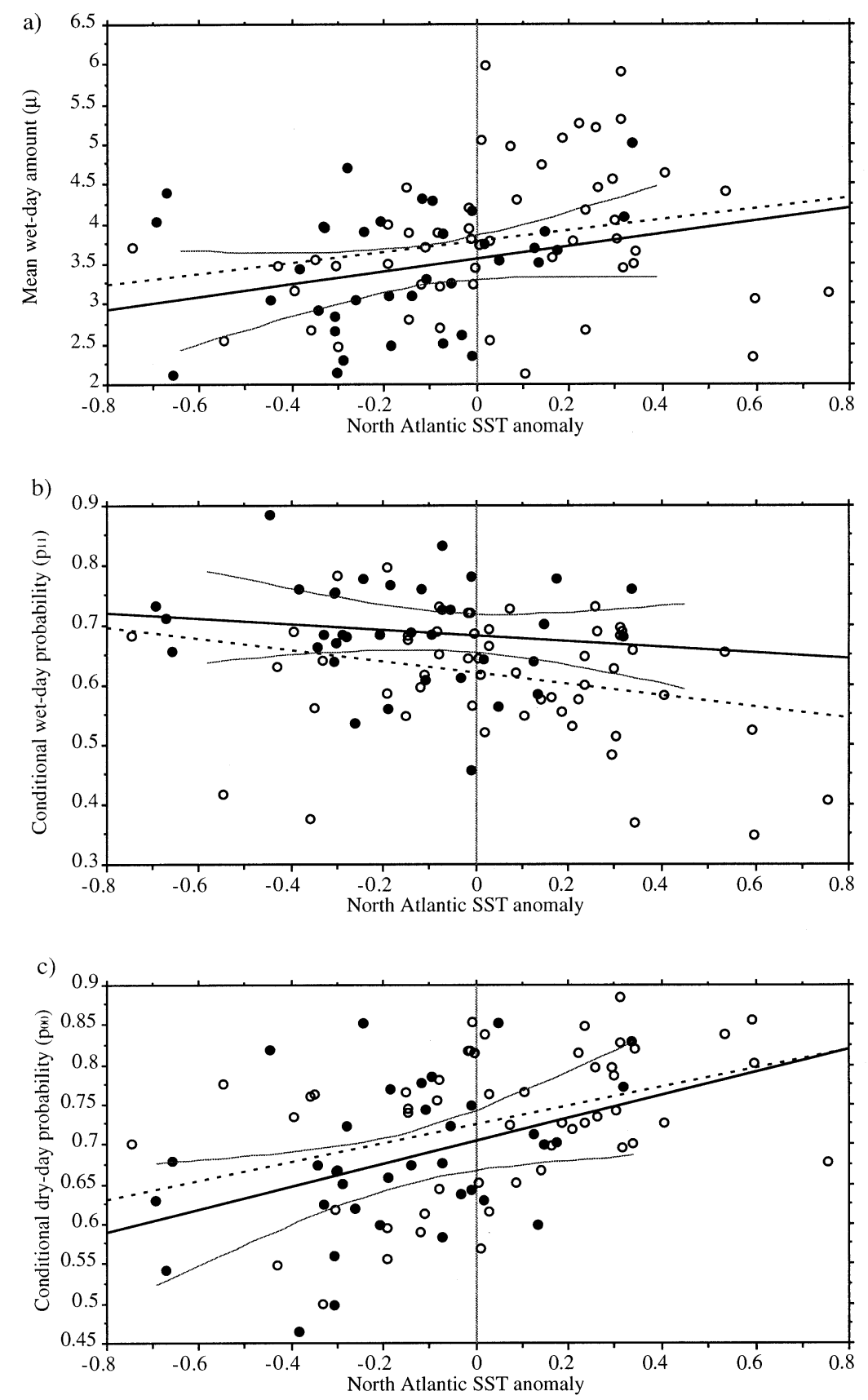

Fig. 9. Relationships between (a) the mean wet-day amount ( $\mu$ ), (b) the conditional wet-day probability $\left(p_{11}\right)$, and $(c)$ the conditional dry-day probability $\left(p_{00}\right)$ at Kemspford and the North Atlantic SST anomalies in MAM. Thick solid line is the linear regression calculated from the 1901-1935 (model calibration period) data. Thin solid lines indicate the $95 \%$ confidence band for this regression. Dashed line is the regression line calculated from the 1936-1990 (model validation period) data. (O) Years after 1935. All regression gradients are significant at the $p<0.1$ level, with the exception of the 1901-1935 $p_{11}$ relationship
Although the NAOI and SST indices have been used as a means of inflating the downscaled monthly precipitation variability, in doing so, the empirical relationships between these indices and the seasonal precipitation parameters $(\mu$, $\left.p_{11}, p_{00}\right)$ are assumed to be stationary. Identical assumptions were made concerning the relationship between daily precipitation renewal/intensity processes and daily vorticity (cf. Wilby 1997). By way of an example, Fig. 9 shows the MAM best-fit, linear regression relationships between the SST anomalies and each of the precipitation parameters at Kempsford for the model calibration (1901-1935) and validation (1936-1990) periods. From Fig. 9a, c it is evident that the assumption of stationarity is valid in the case of the mean wet-day amounts, $\mu$, and the conditional dry-day probabilities, $p_{00}$ : the regression lines based on the 19361990 data lie within the 95\% confidence bands for the earlier period. However, the corresponding regression line for the conditional wet-day probabilities, $\mathrm{p}_{11}$, does lie outside the confidence bands for the 1901-1935 regression line (Fig. 9b). This suggests that, for this site and season at least, the correlation between the precipitation renewal processes, $p_{11}$, and the SST anomaly forcing is not stationary. This effect may be a consequence of differences in the spatial distribution of N orth Atlantic SST anomalies between the calibration and validation periods, implying that simple teleconnection indices (based on a limited number of nodes or spatial domain) do not capture all aspects of the inter-decadal variability. In this respect, empirical orthogonal functions (EOFs) of hemispheric atmospheric circulation or SSTs may yield more stable predictors.

An alternative approach to the downscaling of low-frequency climate variability involves the use of mixtures of stochastic processes. Rather than deriving the time-varying renewal and intensity parameters from regression equations, this approach resamples observed precipitation parameters from categories defined by the low-frequency predictor(s). For example, Katz 
\& Parlange (1996) found that the best precipitation model was obtained when the probability of a wet-day, the intensity mean and the intensity standard deviation (but interestingly not the persistence parameter) were conditioned by an index of monthly mean-sealevel pressure anomalies. When compared with an unconditional precipitation model, the additional complexity of the conditional model in the occurrence process was found to eliminate the overdispersion of total precipitation in January at Chico, California. This study also highlights the merit of using relatively simple indices of low-frequency forcing, indices that should be resolved more realistically in present-day and future climate simulations of GCMs.

Thus, teleconnection indices have clear explanatory power for certain surface variables, in certain regions and seasons, and for the present global climate, but it remains unclear as to what extent the same indices may be used to downscale future climates. This is because the capability of GCM s to represent teleconnection processes (such as ENSO or NAO) is still in its infancy (e.g. Knutson et al. 1997) and because the significance of global warming to such processes is uncertain (e.g. Trenberth \& Hoar 1997). Under climate change conditions regional patterns of SSTs may emerge that have no historical precedent, with serious implications for the validity of empirically based downscaling scenarios.

Ensemble runs of the Hadley Centre AGCM (Atmospheric General Circulation M odel) (HADAM 1) suggest that GCM s can correctly reproduce dominant modes of interannual variability in mean-sea-level pressure and $500 \mathrm{hPa}$ height patterns over the N orth Atlantic, as well as reasonable approximations of the seasonal cycle and interannual variance of the NAO (Davies et al. 1997). However, the significance of NAO or ENSO to future regional climates will depend to a large extent on the magnitude of the predicted temperature increases in the North Atlantic and tropical Pacific respectively ( $M$ eehl \& Washington 1996, Smith \& Ropelewski 1997, Smith et al. 1997). Clearly, further research is required to determine whether or not the inclusion of teleconnection indices in downscaling schemes can help explain interdecadal variations in model parameters, and lead to better representations of low-frequency variability in both present and future climates at regional scales.

Acknowledgements. This research was supported by ACACIA (A Consortium for the Application of Climate Impact Assessments, National Center for Atmospheric Research, Boulder, Colorado) and by ACCORD (Atmospheric Circulation Classification and Regional Downscaling) under the European Community Environment Research Programme (contract: ENV4-CT97-0530). The paper benefited from the helpful and constructive remarks of 3 anonymous referees. NCAR is sponsored by the National Science Foundation.

\section{LITERATURE CITED}

Carson DJ (1998) Seasonal forecasting. Q J R M eteorol Soc $124: 1-26$

Cavazos T (1997) Downscaling large-scale circulation to local winter rainfall in N.E. M exico. Int J Climatol 17:1069-1082

Christensen J H, Machenhauer B, J ones RG, Schär C, Ruti PM, Castro M, Visconti G (1997) Validation of present-day regional climate simulations over Europe: LAM simulations with observed boundary conditions. Clim Dyn 13: 489-506

Colman A (1997) Prediction of summer Central England Temperature from preceding N orth Atlantic winter sea surface temperature. Int J Climatol 17:1285-1300

Conway D, Wilby RL, J ones PD (1996) Precipitation and air flow indices over the British Isles. Clim Res 7:169-183

Crane RG, Hewitson BC (1998) Doubled $\mathrm{CO}_{2}$ precipitation changes for the Susquehanna Basin: downscaling from the GENESIS general circulation model. Int J Climatol 18: $65-76$

Currie RG (1996) Mn and Sc signals in North Atlantic tropical cyclone occurrence. Int J Climatol 16:427-439

Dai A, Fung IY, Del Genio AD (1997) Surface observed global land precipitation variations during 1900-88. J Clim 10: 2943-2962

Davies J R, Rowell DP, Folland CK (1997) North Atlantic and European seasonal predictability using an ensemble of multi-decadal AGCM simulations. Int J Climatol 17: 1263-1284

Folland CK, Parker DE (1995) Correction of instrumental biases in historical sea surface temperature data using a physical approach. Q J R M eteorol Soc 121:319-367

Fraedrich K, Muller K (1992) Climate anomalies in Europe associated with ENSO extremes. Int J Climatol 12:25-31

Giorgi F, Mearns LO (1991) Approaches to the simulation of regional climate change. A review. Rev Geophys 29: 191-216

Hartley S, Keables MJ (1998) Synoptic associations of winter climate and snowfall variability in New England, USA, 1950-1992. Int J Climatol 18:281-298

Hay LE, McCabe GJ, Wolock DM, Ayers MA (1991) Simulation of precipitation by weather type analysis. Water Resour Res 27:493-501

Hostetler SW (1994) Hydrologic and atmospheric models: the (continuing) problem of discordant scales. Clim Change 27:345-350

Hurrell J W (1995) Decadal trends in the North Atlantic Oscillation: regional temperature and precipitation. Science 269:676-679

J ones PD, Hulme M, Briffa KR (1993) A comparison of Lamb circulation types with an objective classification scheme. Int J Climatol 13:655-663

J oyce A, Cox NJ , Kenworthy J M (1998) Inferences regarding raingauge exposure at Durham, 1968-70. Weather 53: 85-90

Karl TR, Wang WC, Schlesinger ME, Knight RW, Portman D (1990) A method of relating general circulation model simulated climate to the observed local climate. Part I: Seasonal statistics. J Clim 3:1053-1079

Katz RW (1977) Precipitation as a chain-dependent process. J Appl Meteorol 16:671-676

Katz RW, Parlange MB (1996) Mixtures of stochastic processes: application to statistical downscaling. Clim Res 7: 185-193

Kim J W, Chang J T, Baker NL, Wilks DS, Gates WL (1984) The statistical problem of climate inversion: determination of the relationship between local and large-scale climate. 
M on Weather Rev 112:2069-2077

Knutson TR, Manabe S, Gu D (1997) Simulated ENSO in a global coupled ocean-atmosphere model: multidecadal amplitude modulation and $\mathrm{CO}_{2}$ sensitivity. J Clim 10: 138-161

Lamb HH (1972) British Isles weather types and a register of the daily sequence of circulation patterns, 1861-1971. Meteorological Office, Geophysical Memoir, No. 116. HMSO, London

Laita M , Grimalt M (1997) Vorticity and pressure anomalies in the Western Mediterranean during El Niño/Southern Oscillation extremes. Int J Climatol 17:475-482

May BR, Hitch TJ (1989) Periodic variations in extreme hourly rainfalls in the United Kingdom. Meteorol M ag 118:45-50

Meehl GA, Washington WM (1996) El Niño-like climate change in a model with increased atmospheric $\mathrm{CO}_{2}$ concentrations. Nature 382:56-60

Nicholls N, Lavery B, Frederiksen C, Drosdowsky W (1996) Recent apparent changes in relationships between the $\mathrm{EI}$ Niño-Southern Oscillation and Australian rainfall and temperature. Geophys Res Lett 23:3357-3360

Osborn TJ (1997) Areal and point precipitation intensity changes: implications for the application of climate models. Geophys Res Lett 24:2829-2832

Pilling C, Wilby RL, J ones J AA 1998) Downscaling of catchment hydrometeorology from GCM output using airflow indices in upland Wales. In: Wheater $\mathrm{H}$, Kirby $\mathrm{C}$ (eds) Hydrology in a changing environment, Vol 1. Wiley, Chichester, p 191-208

Plaut G, Ghil M, Vautard R (1995) Interannual and interdecadal variability in 335 years of Central England Temperature. Science 268:710-713

Rodo X, Baert E, Comin FA (1997) Variations in seasonal rainfall in Southern Europe during the present century: relationships with the North Atlantic Oscillation and the EI Nino-Southern Oscillation. Clim Dyn 13:275-284

Rodriguez-Puebla C, Encinas AH, Nieto S, Garmendia J (1998) Spatial and temporal patterns of annual precipitation variability over the Iberian Peninsula. Int J Climatol 18:299-316

Schär C, Frei C, Lüthi D, Davies HC (1996) Surrogate climate change scenarios for regional climate models. Geophys Res Lett 6:669-672

Schüepp M (1979) Witterungsklimatologie, Beiheft zu den Annalen der Schweizerischen Meteorologischen Anstalt. Swiss M eteorological Institute, Zurich

Semenov M A, Barrow EM (1997) Use of a stochastic weather generator in the development of climate change scenarios. Clim Change 35:397-414

Shabbar A, Khandekar M (1996) The impact of El NinoSouthern Oscillation on the temperature field over Canada. Atmos Ocean 34:401-416

Editorial responsibility: Mike Hulme, Norwich, United Kingdom
Simmonds I, Hope P (1997) Persistence characteristics of Australian rainfall anomalies. Int J Climatol 17:597-613

Smith IN, Dix M, Allan RJ (1997) The effect of greenhouse SSTs on ENSO simulations with an AGCM. J Clim 10: 342-352

Smith TM, Ropelewski CF (1997) Quantifying southern oscillation-precipitation relationships from an atmospheric GCM. J Clim 10:2277-2284

Sweeney J C, O'Hare GP (1992) Geographical variations in precipitation yields and circulation types in Britain and Ireland. Trans Inst Br Geogr 17:448-463

Todorovic P, Woolhiser DA (1975) A stochastic model of $n$-day precipitation. J Appl Meteorol 14:17-24

Trenberth KE, Hoar TJ (1997) El Niño and climate change. Geophys Res Lett 24:3057-3060

von Storch H, Zorita E, Cubasch U (1993) Downscaling of global climate change estimates to regional scales: an application to Iberian rainfall in wintertime. J Clim 6: 1161-1171

Widmann M, Schär C (1997) A principal component and longterm trend analysis of daily precipitation in Switzerland. Int J Climatol 17:1333-1356

Wigley TML, J ones PD (1987) England and Wales precipitation: a discussion of recent changes in variability and an update to 1985. J Climatol 7:231-246

Wigley TML, J ones PD, Briffa KR, Smith G (1990) Obtaining sub-grid scale information from coarse resolution general circulation model output. J Geophys Res 95:1943-1953

Wilby RL (1993) Evidence of ENSO in the synoptic climate of the British Isles since 1880. Weather 48:234-239

Wilby RL (1997) Nonstationarity in daily precipitation series: implications for GCM downscaling using atmospheric circulation indices. Int J Climatol 17:439-454

Wilby RL, Wigley TML (1997) Downscaling general circulation model output: a review of methods and limitations. Progr Phys Geogr 21:530-548

Wilby RL, Barnsley N, O'Hare G (1995) Rainfall variability associated with Lamb weather types: the case for incorporating weather fronts. Int J Climatol 15:1241-1252

Wilby RL, O'Hare G, Barnsley N (1997) The North Atlantic Oscillation and British Isles climate variability 1865-1995. Weather 52:266-276

Wilby RL, Hassan H, Hanaki K (1998) Statistical downscaling of hydro-meteorological variables using general circulation model output. J Hydrol 205:1-19

Winkler J A, Palutik of J P, Andresen J A, Goodess CM (1997) The simulation of daily temperature series from GCM output. Part II: Sensitivity analysis of an empirical transfer function methodology. J Clim 10:2514-2532

Woodhouse CA (1997) Winter climate and atmospheric circulation patterns in the Sonoran desert region, USA. Int J Climatol 17:859-873

Submitted: A pril 21, 1998; Accepted: September 4, 1998

Proofs received from author(s): October 13, 1998 